\title{
Passive anterior tibia translation in anterior cruciate ligament-injured, anterior cruciate ligament-reconstructed and healthy knees: a systematic review
}

\author{
M. N. J. Keizer ${ }^{1}$ - E. Otten ${ }^{1}$ \\ Received: 3 February 2018 / Accepted: 6 October 2018 / Published online: 16 October 2018 \\ (c) The Author(s) 2018
}

\begin{abstract}
Anterior tibia translation (ATT) is mainly prevented by the anterior cruciate ligament. Passive ATT tests are commonly used to diagnose an anterior cruciate ligament (ACL) injury, to select patients for an ACL reconstruction (ACLR), and as an outcome measure after an ACLR. The aim of this review was to present an overview of possible factors determining ATT. A second purpose was to give a summary of the ATT measured in the literature in healthy, ACL-injured and ACLR knees and a comparison between those groups. A literature search was conducted with PubMed. Inclusion criteria were full-text primary studies published in English between January 2006 and October 2016. Studies included reported ATT in explicit data in healthy as well as ACL-injured or ACLR knees or in ACL-injured as well as ACLR knees. Sixty-one articles met inclusion criteria. Two articles measured the ATT in healthy as well as ACL-injured knees, 51 in ACL-injured as well as in ACLR knees, three in ACLR as well as in healthy knees and three in healthy, ACL-injured and ACLR knees. A difference in ATT is found between healthy, contralateral, ACLR and ACL-injured knees and between chronic and acute ACL injury. Graft choices and intra-articular injuries are factors which could affect the ATT. The mean ATT was lowest to highest in ACLR knees using a bone-patella tendon-bone autograft, ACLR knees using a hamstring autograft, contralateral healthy knees, healthy knees, ACLR knees with an allograft and ACL-injured knees. Factors which could affect the ATT are graft choice, ACL injury or reconstruction, intra-articular injuries and whether an ACL injury is chronic or acute. Comparison of ATT between studies should be taken with caution as a high number of different measurement methods are used. To be able to compare studies, more consistency in measuring devices used should be introduced to measuring ATT. The clinical relevance is that an autograft ACLR might give better results than an allograft ACLR as knee laxity is greater when using an allograft tendon.
\end{abstract}

Level of evidence III.

Keywords Knee laxity $\cdot$ Influences $\cdot$ ACL $\cdot$ Allograft $\cdot$ Autograft

\section{Introduction}

Anterior tibia translation (ATT) is mainly prevented by the anterior cruciate ligament (ACL) [1]. An ACL injury results in higher ATT with respect to the femur. To reduce the increased ATT after an ACL injury, an ACL reconstruction (ACLR) is warranted [2]. Passive ATT tests are commonly

\footnotetext{
M. N. J. Keizer

m.n.j.keizer@umcg.nl

1 Center for Human Movement Science, University Medical Center Groningen, University of Groningen, Groningen, The Netherlands
}

used to diagnose an ACL injury and to select patients for an ACLR [3]. Moreover, passive ATT tests are commonly used as an outcome measure after an ACLR, for example, to compare knee laxity after an ACLR using different types of grafts (i.e. $[4,5]$ ).

Several methods can be used to assess the ATT. These tests could either be clinical tests, i.e. the Lachman test, or instrumental measuring methods (i.e. [6, 7]). The most frequently used instrumental measuring method is the KT-1000 arthrometer (KT-1000) (Medmetric Corp., San Diego, CA, USA) developed by Dale Daniel in 1983 [8]. Using the KT-1000 and its successors, the KT-2000 [9] and the ComputKT, an examiner applies forces to the tibia using a handle on top of the device. The anterior-posterior displacement is 
determined by the distance or relative motion between two sensing paddles: one on the patella and one on the tibial tubercle. The device is calibrated by the determination of the zero point which is done by performing several anterior and posterior translations of the tibia. Visual-manual records are displayed, and audible tones are reached at $15 \mathrm{~N}, 20 \mathrm{~N}$, $30 \mathrm{~N}, 67 \mathrm{~N}, 89 \mathrm{~N}, 133 \mathrm{~N}, 134 \mathrm{~N}$, maximal manual (Mm) or maximal personal (Mp) forces. The KT-2000 and the ComputKT have improved data visualisation.

Other methods to assess the ATT are the Kneelax (MR Systems, Haarlem, the Netherlands [10]), the Rolimeter (Aircast, Vista, CA, USA [11]), the Telos Stress Device (H.Tulaszewski, 6302 LICH-Ober-Blessingen, West Germany [12]), the electromagnetic measurement system (EMC) (FASTRAK, Polhemus, VT, USA [13]), the radiostereometric analysis (RSA [12]), fluoroscopic measurements (FM) (BV-29; Philips, Best, the Netherlands) and (computerassisted) navigation systems. The Kneelax is similar to the KT-1000, but the updated recording process allows digital recording of ATT at the same forces as the KT-1000. The Rolimeter can measure the ATT during the Lachman, anterior drawer and 'step-off' tests and is easy in use and cheap. The ends of the device are placed on the mid-patella and tibia, and ATT is measured using a calibrated stylus with 2-mm markers. The Telos Stress Device in combination with a radiostereometric analysis is expensive and results in radiation exposure. When mechanically a force of $150 \mathrm{~N}, 250 \mathrm{~N}$ or maximal manual $(\mathrm{Mm})$ is applied, a stress radiograph is made. Recently, the Telos Stress Device is updated allowing to determine the ATT with a linear optical encoder and without radiographs.

The electromagnetic measurement system (EMS) is an in vivo noninvasive system using an electromagnetic sensor during the pivot-shift test. It monitors instantaneous 3D position and calculates the 3D acceleration of the motion. The radiostereometric analysis (RSA), developed by Selvik et al., has a high accuracy of $0.1-\mathrm{mm}$ displacement. It is an invasive method relying on the implantation of tantalum beads. During a fluoroscopic measurement (FM), the device is placed on the medial side of the knee, and X-ray fluoroscopy captures the knee motion during a Lachman test. A (computer-assisted) navigation system can be used during surgery to measure three-dimensional knee kinematics when applying a specific amount of force on the tibia.

A variety of factors could determine the ATT. It is necessary to identify possible factors which could determine the ATT as knee laxity is shown to be associated with osteoarthritis $[14,15]$ and an increased chance of knee injuries [16], in particular an ACL injury $[17,18]$. Besides, it is not clearly reported what the range of ATT is in healthy, ACL-injured and ACLR knees.

The main purpose of the current systematic review was to give an overview of possible factors determining the ATT.
A second purpose was to present a summary of the ATT measured in the available literature in healthy, ACL-injured and ACLR knees and a comparison between those groups.

\section{Methods}

\section{Inclusion criteria}

In order to identify articles for inclusion, a systematic literature search was conducted with the PubMed electronic database on the 6 October 2016. The search terminology was based on the query "(Knee OR ACL) AND (Laxity OR Anterior Translation) NOT (cadaveric OR Shoulder OR Ankle OR PCL OR TKA OR TKR)".

Titles, abstracts and full texts were analysed by the first author (M.N.J.K). Articles were included if they were: (1) full-text primary studies; (2) published in the English language; (3) published between the 1 January 2006 and 1 October 2016, to reduce the high number of papers and as the measurement methods are improved; (4) studies that reported possible factors determining the ATT; (5) studies that reported ATT in either ACL-injured as well as in ACLR knees; in ACL-injured as well as in healthy knees; or in ACLR as well as in healthy knees; (6) studies that displayed the ATT in explicit data. Review articles were excluded. Articles were excluded when they only measured ATT in ACL-injured, ACLR or healthy participants, did not display ATT in explicit data, measured ATT in participants with additional (knee) injuries, measured tibia position instead of ATT or measured ATT in an active situation.

After identification of the articles, the Newcastle-Ottawa Scale was used by the first author (M.N.J.K.) to appraise the studies that were identified for inclusion in this review [19]. All included studies were found to have an average to good study quality with a score of 6 to 9 out of 9 . No reasons were found to assume biases in the data.

\section{Study characteristics}

Articles which met inclusion criteria were analysed for patient demographics, measuring methods to access ATT, the ATT, factors determining the ATT, and, for articles with ACLR participants, type of graft used.

Fifty-eight articles reported factors which may determine the ATT. Two articles were identified reporting ATT in ACL-injured as well as healthy or contralateral healthy knees, 51 articles were identified reporting ATT in ACLinjured as well as ACLR knees, and 3 articles were identified reporting ATT in ACLR as well as in healthy knees. Three articles were included in all three groups as they reported ATT in healthy, ACL-injured and ACLR knees. For analyses, sixty-one articles were included (Fig. 1). 
Fig. 1 Flow chart of the literature search

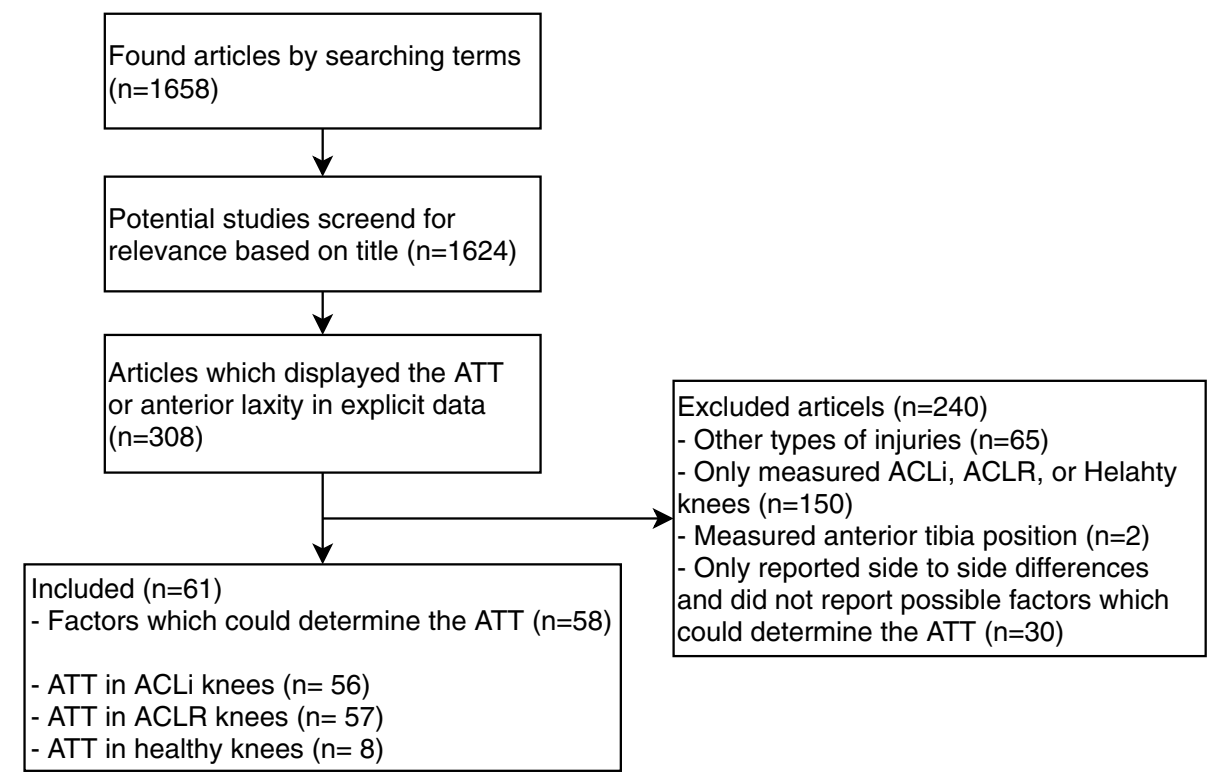

The number of included participants per study ranged from 11 to 375. The average age of the participants included per study ranged from 13.9 to 54.4 year. Four studies did not include information on gender. In total, 2.583 of the patients were male, and 1651 were female. Forty-four of the studies used hamstring autografts for ACLR, 15 of the studies used bone-patellar tendon autografts for ACLR, and six of the studies used allograft for ACLR.

\section{Synthesis of results}

The mean ATT was measured for all measurement methods as well as for ACL-injured, ACL-reconstructed (split by type of graft) and (contralateral) healthy knees. These data were compared between groups.

\section{Statistical analysis}

In this review, the results of articles with a significant difference of $p<0.05$ were declared as significant results.

An independent two-way factorial analysis of variance with interaction was conducted to find the effect of the type of devices and the groups (healthy, contralateral healthy, ACL-injured, ACLR with hamstring autograft tendon, ACLR with bone-patella tendon-bone autograft tendon and ACLR with allograft tendon knees) on the ATT, to find whether there is an interaction between groups and type of devices and to evaluate the coefficients of the groups and devices.

\section{Results}

\section{Possible factors which could determine the ATT}

Chen et al. [20] found that patients which had an acute ACL-injured $(n=27)$ had significantly lower ATT in comparison with patients who had chronic ACL-injured $(n=28)$. Christino et al. [6] found that ATT in patients without intra-articular injuries $(n=19)$ was significantly lower than in patients with intra-articular injuries $(n=11)$.

Of sixteen studies only two articles found significant differences in ATT between using a single-bundle and a double-bundle autograft tendon for ACLR in favour of a double-bundle autograft $[4,21]$. Three of the six articles which compared allograft use and autograft use found a significant difference in favour of an autograft tendon [22-24]. Only one out of five studies which compared BPTB autograft and hamstring autograft use reported a significant difference in favour of hamstring autografts [23]. A significantly higher ATT was found in patients who underwent ACLR using a 4-strand compared to an 8 -strand hamstring autograft [24], in patients who underwent ACLR using a Leeds-Keio ligament compared to using a BPTB autograft at 2 years after reconstruction [25] and in patients who underwent ACLR using a calcium phosphate-hybridised BPTB autograft in comparison with the conventional method [26].

Two studies reported significant differences between graft fixation methods [27, 28]. However, others did not report any differences in graft fixation methods [21, 29-34]. For all comparisons see Table 1. 
Table 1 Factors which might determine the anterior tibia translation

\begin{tabular}{|c|c|c|}
\hline Study & Compared & Conclusion \\
\hline$[20]$ & Acute versus chronic ACL-injured knees & Chronic $>$ acute* \\
\hline [6] & Before ACLR in patients with versus without intra-articular injuries & With > without* \\
\hline [35] & Males versus females & Females $>$ males \\
\hline$[36]$ & Males versus females & Females $>$ males \\
\hline$[37]$ & Males versus females & Females $>$ males \\
\hline [4] & SB versus DB hamstring aut & $\mathrm{SB}>\mathrm{DB}^{*}$ \\
\hline$[38]$ & SB versus DB hamstring aut & $\mathrm{DB}>\mathrm{SB}$ \\
\hline [39] & SB versus DB hamstring aut & $\mathrm{SB}>\mathrm{DB}$ \\
\hline [40] & SB versus DB hamstring aut & $\mathrm{SB}>\mathrm{DB}$ \\
\hline [41] & SB versus DB hamstring aut & $\mathrm{SB}>\mathrm{DB}$ \\
\hline$[42]$ & SB versus DB hamstring aut & $\mathrm{DB}>\mathrm{SB}$ \\
\hline [43] & SB versus DB hamstring aut & $\mathrm{SB}>\mathrm{DB}$ \\
\hline$[44]$ & SB versus DB hamstring aut & $\mathrm{DB}>\mathrm{SB}$ \\
\hline$[45]$ & SB versus DB hamstring aut & $\begin{array}{l}0^{\circ}, 30^{\circ} \text {, and } 90^{\circ}: \mathrm{SB}>\mathrm{DB} \\
60^{\circ}: \mathrm{DB}>\mathrm{SB}\end{array}$ \\
\hline [46] & SB versus DB hamstring aut & $\mathrm{SB}>\mathrm{DB}$ \\
\hline [47] & SB versus DB hamstring aut & $\mathrm{DB}>\mathrm{SB}$ \\
\hline [48] & SB versus DB hamstring aut & $\mathrm{SB}>\mathrm{DB}$ \\
\hline [49] & SB versus DB hamstring aut & $\mathrm{DB}>\mathrm{SB}$ \\
\hline$[50]$ & SB versus DB hamstring aut & $\mathrm{SB}>\mathrm{DB}$ \\
\hline$[51]$ & SB versus DB BPTB all & $\mathrm{SB}>\mathrm{DB}$ \\
\hline$[52]$ & TB versus SB hamstring aut & $\begin{array}{l}\text { KT-1000: TB > SB } \\
\text { Telos: SB > TB }\end{array}$ \\
\hline [19] & Anatomic versus nonanatomic DB hamstring & $\begin{array}{l}\mathrm{SB}>\text { anatomic* } \\
\text { Nonanatomic }>\text { anatomic }\end{array}$ \\
\hline$[53]$ & All versus hamstring aut & All $>$ aut \\
\hline$[28]$ & All versus BPTB aut & All $>$ aut \\
\hline$[54]$ & All versus hamstring aut & All > aut* \\
\hline$[55]$ & Hamstring aut versus irradiated all & All > aut* \\
\hline$[22]$ & ВРТВ aut versus fresh-frozen all (all1) or y-irradiated all (all2) & All2* $>$ all $1>$ aut \\
\hline$[56]$ & All free tendon Achilles versus hamstring aut & All $>$ aut \\
\hline$[23]$ & BPTB versus hamstring aut & BPTB $>$ hamstring* \\
\hline$[57]$ & BPTB versus hamstring aut & Hamstring $>$ BPTB \\
\hline$[58]$ & BPTB versus hamstring aut & Hamstring $>$ BPTB \\
\hline$[59]$ & BPTB versus hamstring aut & Hamstring $>$ BPTB \\
\hline$[60]$ & DB hamstring (1) versus BPTB (2) versus BPTB_L (3) & $\begin{array}{l}\text { Medial: } 3>2>1 \\
\text { Lateral: } 2>3>1 \\
\text { BPTB_L reduced most* }\end{array}$ \\
\hline$[61]$ & DB hamstring aut versus aug & $\begin{array}{l}\text { KT-1000: DB > aug } \\
\text { Telos: aug > DB }\end{array}$ \\
\hline$[62]$ & 4-Strand versus 8 -strand hamstring aut & 4-strand $>8$-strand \\
\hline$[63]$ & Hamstring versus quadriceps aut & Quadriceps $>$ hamstring \\
\hline$[25]$ & BPTB versus LK & $\begin{array}{l}2 \text { y after ACLR: } L K>\text { BPTB* } \\
5 \text { y after ACLR: } B P T B>\text { LK }\end{array}$ \\
\hline$[64]$ & Qf versus BPTB & BPTB $>$ Qf \\
\hline$[65]$ & Cas versus non-Cas surgery & Non-Cas $>$ Cas \\
\hline$[66]$ & High versus low tension BPTB or hamstring aut & High $>$ low \\
\hline$[26]$ & $\mathrm{CaP}$ versus CM BPTB & $\mathrm{CM}>\mathrm{CaP}^{*}$ \\
\hline$[67]$ & A20 versus $\mathrm{P} 20$ versus A20P0 versus A20P20 versus A20P45 bundle fixation & $\begin{array}{l}\mathrm{P} 20>\mathrm{A} 20^{*} \\
\mathrm{~A} 20>\mathrm{A} 20 \mathrm{P} 0 * \\
\mathrm{P} 20>\mathrm{A} 20>\mathrm{A} 20 \mathrm{P} 20^{*} \\
\mathrm{P} 20>\mathrm{A} 20>\mathrm{A} 20 \mathrm{P} 45^{*}\end{array}$ \\
\hline
\end{tabular}


Table 1 (continued)

\begin{tabular}{lll}
\hline Study & Compared & Conclusion \\
\hline$[68]$ & With versus without navigation system & With $>$ without \\
{$[21]$} & TT versus AM SB hamstring aut & TT $>$ AM \\
{$[69]$} & Metal versus PLLA screw & Metal $=$ PLLA \\
{$[70]$} & BioCryl versus RigidFix fixation & BioCryl $>$ RigidFix \\
{$[27]$} & Cortical with versus without aperture fixation & Without $>$ with* \\
{$[29]$} & TransFix versus Endobutton fixation & Endobutton $>$ TransFix \\
{$[31]$} & TransFix versus bioscrew fixation & Bioscrew $>$ TransFix \\
{$[71]$} & Bioabsorbable versus metal screw fixation & Metal $>$ bioabsorbable \\
{$[72]$} & Metal versus PLLA screw hamstring aut & PLLA $>$ metal \\
{$[73]$} & RigidFix and intrafix (1) versus RigidFix and bioscrew (2) versus bioscrew and intrafix (3) & $3>2>4>1$ \\
{$[74]$} & versus bioscrew and bioscrew fixation (4) & $2>1$ \\
{$[75]$} & Femoral knot/press fit (1) versus femoral interference screw fixation (2) & Late $>$ early \\
{$[76]$} & Early extension versus late extension during rehabilitation & Greater $>$ lower \\
{$[77]$} & Greater than 20\% versus lower than 20\% strength deficit & 3 Days $>2$ weeks \\
{$[78]$} & Three-day versus 2-week immobilisation & Nonbrace $>$ brace \\
{$[34]$} & Brace versus nonbrace after ACLR & LH $>$ RH*
\end{tabular}

$A C L$ anterior cruciate ligament, $A C L R$ anterior cruciate ligament reconstruction $S B$ single bundle, $D B$ double bundle, all allograft, aut autograft, $B P T B$ bone-patellar tendon-bone, $T B$ triple bundle, $B P T B-L$ mono-bundle BPTB combined with extra-articular reconstruction, aug remnantpreserving augmentation, $L K$ Leeds-Keio ligament, $y$ years, $Q f$ quadruple flexor, Cas computer-assisted surgery, $A 20$ anteromedial bundle fixation only at $20^{\circ}$ of flexion, $P 20$ posterolateral bundle fixation only at $20^{\circ}$ of flexion, $A 20 P 0$ anteromedial bundle fixation at $20^{\circ}$ and posterolateral bundle fixation at $0^{\circ}$ of flexion, $A 20 P 20$ anteromedial bundle fixation at $20^{\circ}$ and posterolateral bundle fixation at $20^{\circ}$ of flexion, $A 20 P 45$ anteromedial bundle fixation at $20^{\circ}$ and posterolateral bundle fixation at $45^{\circ}$ of flexion, $T T$ transtibial femoral tunnel preparation, $A M$ anteromedial femoral tunnel preparation, $C a P$ hybridising calcium phosphate, $C M$ conventional method, $P L L A$ biodegradable interference screw, $L H$ lefthanded, $R H$ right-handed

*Significant

\section{Factor analysis of groups and devices on ATT}

Two devices (FM and EMS) showed much higher ATT than the other devices, and therefore, these two devices were excluded for calculation of mean ATT per group. A nonsignificant interaction between groups and devices was seen $(p=0.73)$. No $p$ values could be calculated for the groups and devices separately, as the number of observations of some groups and some devices was too low. The coefficients of all groups ranged from -1.75 to 2.89 with a mean of 0.00 . The coefficients of all devices ranged from -3.30 to 4.07 with a mean of 0.21 . In Table 2 the coefficients of the groups, of devices which were lower than -1 and higher than 1 , and of the interaction which were lower than -3 and higher than 3 are reported.

For the ATT for each device per group see Fig. 2.

Table 2 Highest coefficients of an independent two-way factorial analysis of variance with interaction. Only coefficients for devices lower than -1 and higher than 1 are reported. Only interaction coefficients lower than -3 and higher than 3 are reported

\begin{tabular}{|c|c|c|c|c|c|c|c|}
\hline Group & Coef & Device & Coef & Device & Coef & Interaction & Coef \\
\hline ACL-injured & 2.89 & ComputKT $(134 \mathrm{~N})$ & 4.07 & KT-1000 (133 N) & -1.26 & Telos* healthy & 4.51 \\
\hline Contralateral & 0.85 & Navigation & 3.59 & Kneelax $(98 \mathrm{~N})$ & -1.45 & Telos $(150 \mathrm{~N}) *$ ACL-injured & 4.17 \\
\hline Allograft & -0.18 & Navigation (MF) & 2.64 & KT-1000 (15 N) & -1.84 & Rolimeter $(\mathrm{Mm}) *$ contralateral & 3.82 \\
\hline Healthy & -0.24 & KT-1000 (Mm) & 1.84 & Telos $(150 \mathrm{~N})$ & -2.56 & KT-1000 $(89 \mathrm{~N}) *$ hamstring & 3.58 \\
\hline ВРТВ & -1.53 & KT-1000 (300 N) & 1.68 & Kneelax (132 N) & -2.79 & Navigation $(100 \mathrm{~N}) *$ ACL-injured & 3.24 \\
\hline \multirow[t]{3}{*}{ Hamstring } & -1.75 & Rolimeter & 1.66 & Rolimeter (Mm) & -3.30 & $\mathrm{RSA} * \mathrm{BPTB}$ & 3.02 \\
\hline & & KT-1000 (134 N) & 1.02 & & & ComputKT $(134 \mathrm{~N}) *$ ACL-injured & -3.16 \\
\hline & & KT-2000 (Mm) & 1.01 & & & KT-1000 (Mp) * ACL-injured & -3.38 \\
\hline
\end{tabular}

Coef coefficient 


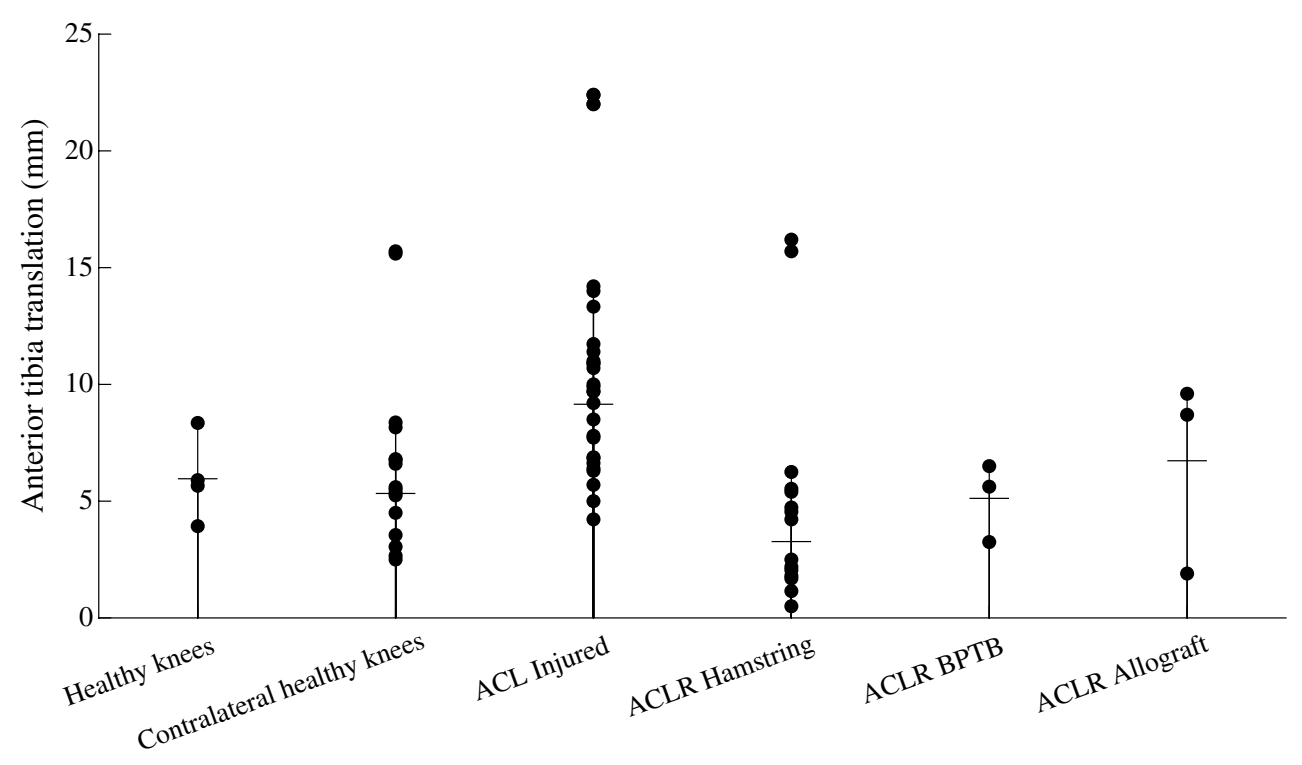

Fig. 2 Absolute anterior tibia translation per group (healthy, contralateral healthy, ACL injured, ACL reconstructed with hamstring autograft tendon, ACL reconstructed with bone-patella tendon-bone autograft tendon and ACL reconstructed with allograft tendon knees)

\section{Discussion}

The mean finding of this review was that graft choice, ACL injury or reconstruction, intra-articular injuries and whether an ACL injury is chronic or acute are factors which could determine the ATT. Other possible factors, such as fixation techniques, were inconclusive. The mean absolute ATT is, respectively, lowest to highest in ACLR knees with a BPTB autograft $(3.25 \mathrm{~mm})$, ACLR knees with a hamstring autograft $(3.27 \mathrm{~mm})$, contralateral healthy knees $(5.33 \mathrm{~mm})$, healthy knees $(5.96 \mathrm{~mm})$, ACLR knees with an allograft tendon $(6.73 \mathrm{~mm})$ and ACL-injured knees $(9.15 \mathrm{~mm})$.

The mean ATT measured in ACLR knees with an allograft was twice as high as the ATT measured in ACLR knees with an BPTB autograft. This finding is consistent with the finding of Tian et al. [55], however, in contrast with the finding of Ghodadra et al. [28] who did not report a significant difference between BPTB autograft and allograft use. In addition, Laoruengthana et al. [23] reported that ATT is significantly higher in ACLR knees with BPTB autograft compared to ACLR knees with hamstring autograft. This is in contrast with the data presented in this review. The mean ATT in knees with a BPTB autograft was only $0.02 \mathrm{~mm}$ lower than in ACLR knees with a hamstring autograft.

The methods used to assess ATT might have introduced a systematic measurement error. In healthy knees, ATT ranged from $3.93 \mathrm{~mm}$ (KT-1000 89N) to $8.35 \mathrm{~mm}$ (ComputKT) and in contralateral healthy knees from $2.5 \mathrm{~mm}$ (KT-1000 $67 \mathrm{~N}$ ) to $15.7 \mathrm{~mm}$ (EMS). In addition, the range of coefficients measured using an independent two-way factorial of each device (black dots). The black horizontal lines indicate the mean ATT of the groups. The six separate dots indicate the devices excluded from analysis

analysis of variance with interaction was greater in range for the devices (range: -3.30 to 4.07 ) in comparison with the groups (range: -1.75 to 2.89 ). Therefore, comparison of ATT between devices should be taken with caution as the choice of measuring device might be paramount. However, some interactions between devices and groups were strong (Table 2), for example: the coefficient of the interaction between the ComputKT and BPTB group was -3.16 . Therefore, the difference in ATT between devices might also have been caused by differences in characteristic of subjects measured in the studies in which those devices were used. More consistency in measuring device used to assess ATT should be introduced. Pugh et al. [30] in their review suggest that the KT-1000 and the Rolimeter provide better results than the Telos Stress Radiography and some other devices not covered in this review. Fortunately, the KT-1000 arthrometer is the most frequently used.

For almost all devices a variety of forces can be used to measure the ATT. The relation between forces and ATT is reported by Lin et al. [33] for healthy knees and ACL-injured knees. They reported a significantly larger displacement and a significantly larger stiffness of the injured knee compared to healthy knees. In line with these results the mean ATT of the studies in this review was smaller in healthy and contralateral knees in comparison with ACL-injured knees. However, the relationship between force and ATT is not seen in the data of the current review. This might be due to differences between studies in, i.e. subject characteristics and other factors which could also have determined the ATT. For example, a significant difference in ATT measured using a 
KT-1000 between right-handed physiotherapists and lefthanded physiotherapists was reported by Sernert et al. [34]. A between-studies comparison of ATT should be taken with caution, especially when different measurement methods or forces are used.

Muscle activity might also have determined the ATT. Klyne et al. [79] found in patients with an ACL injury a relation between ATT in a passive situation and prolonged muscle activity of the medial gastrocnemius during a jump test. Barcellona et al. [80] found that hamstrings activity reduces anterior knee laxity in a passive situation in ACLinjured patients. This indicates that patients with an ACL injury might compensate for knee laxity by increasing the duration of muscle activity. However, Goradia et al. [76] did not find a difference in ATT between patients with strength deficit and patients without strength deficit. Kvist [81] found that there is no correlation between ATT in a passive situation and ATT in an active situation, which might indicate that muscle activity does play a role in the control of ATT during activity. Future studies could investigate the effect of muscle activity on ATT and could investigate ATT in an active situation, i.e. by using the method to assess ATT of Boeth et al. [82].

Some limitations of this review should be addressed. Systematic reviews are limited by the weaknesses of each study. This might include a small number of participants, a shortterm follow-up time and a high variability of participants. However, no reasons were found to assume biases in the data. One article which was determined to have a poor quality was excluded from further analysis. In addition, a limitation of this review was the large variety of measurement devices used to assess the ATT, which made a comparison between studies difficult. However, this also makes clear that more consistency should be introduced in measuring method for ATT.

\section{Conclusion}

Surprisingly reported ATT, in comparison with healthy knees, is higher after an ACLR using an allograft tendon and lower in knees using a bone-patella tendon-bone autograft. In addition, ATT was significantly higher in chronic than in acute ACL injuries and in knees with intra-articular injuries compared to knees without intra-articular injuries. Inconclusive results were found for other factors such as fixation techniques. When excluding two devices which measured much higher ATT than the other devices, mean ATT was lowest to highest in ACLR knees using a bone-patella tendon-bone (BPTB) autograft, ACLR knees using a hamstring autograft, contralateral healthy knees, healthy knees, ACLR knees with an allograft and ACL-injured knees. Between-studies comparison of the ATT should be taken with caution as lots of different measurement methods with different forces were used to measure the ATT. To make the compatibility of studies more reliable, more consistency in measuring methods to assess ATT should be introduced. The clinical relevance of this study is that even though the ATT was smaller after an ACLR in comparison with ACL-injured knees, using an allograft tendon, the ATT was greater than healthy knees, whereas by using an autograft tendon the ATT was smaller than in healthy knees. An increase in ATT is found to be a risk factor for osteoarthritis and a chance of knee injuries; therefore, an autograft ACLR might give better results in comparison with an allograft ACLR.

\section{Compliance with ethical standards}

Conflict of interest The authors declare that they have no conflict of interest.

Open Access This article is distributed under the terms of the Creative Commons Attribution 4.0 International License (http://creativeco mmons.org/licenses/by/4.0/), which permits unrestricted use, distribution, and reproduction in any medium, provided you give appropriate credit to the original author(s) and the source, provide a link to the Creative Commons license, and indicate if changes were made.

\section{References}

1. Domnick C, Raschke MJ, Herbort M (2016) Biomechanics of the anterior cruciate ligament: physiology, rupture and reconstruction techniques. World J Orthop 7(2):82

2. Halonen K, Mononen M, Toÿräs J, Kröger H, Joukainen A, Korhonen R (2016) Optimal graft stiffness and pre-strain restore normal joint motion and cartilage responses in ACL reconstructed knee. J Biomech 49(13):2566-2576

3. Vergis A, Hindriks M, Gillquist J (1997) Sagittal plane translations of the knee in anterior cruciate deficient subjects and controls. Med Sci Sports Exerc 29(12):1561-1566

4. Aglietti P, Giron F, Losco M, Cuomo P, Ciardullo A, Mondanelli N (2010) Comparison between single-and double-bundle anterior cruciate ligament reconstruction a prospective, randomized, single-blinded clinical trial. Am J Sports Med 38(1):25-34

5. Arbes S, Resinger C, Vécsei V, Nau T (2007) The functional outcome of total tears of the anterior cruciate ligament (ACL) in the skeletally immature patient. Int Orthop 31(4):471-475

6. Christino MA, Vopat BG, Waryasz GR, Mayer A, Reinert SE, Shalvoy RM (2014) Adolescent differences in knee stability following computer-assisted anterior cruciate ligament reconstruction. Orthop Rev (Pavia) 6(4):5653

7. Isberg J, Faxèn E, Brandsson S, Eriksson BI, Kärrholm J, Karlsson J (2006) KT-1000 records smaller side-to-side differences than radiostereometric analysis before and after an ACL reconstruction. Knee Surg Sports Traumatol Arthrosc 14(6):529-535

8. Sernert N, Kartus J, Kohler K, Ejerhed L, Karlsson J (2001) Evaluation of the reproducibility of the KT-1000 arthrometer. Scand J Med Sci Sport 11(2):120-125

9. Myrer JW, Schulthies SS, Fellingham GW (1996) Relative and absolute reliability of the KT-2000 arthrometer for uninjured knees. Am J Sports Med 24(1):104-108 
10. Paine R, Lowe W (2012) Comparison of Kneelax and KT-1000 knee ligament arthrometers. J Knee Surg 25(2):151-154

11. Balasch H, Schiller M, Friebel H, Hoffmann F (1999) Evaluation of anterior knee joint instability with the Rolimeter. Knee Surg Sports Traumatol Arthrosc 7(4):204-208

12. Sørensen OG, Larsen K, Jakobsen BW, Kold S, Hansen TB, Lind M, Søballe K (2011) The combination of radiostereometric analysis and the Telos stress device results in poor precision for knee laxity measurements after anterior cruciate ligament reconstruction. Knee Surg Sports Traumatol Arthrosc 19(3):355-362

13. Araki D, Kuroda R, Kubo S, Nagamune K, Hoshino Y, Nishimoto K, Takayama K, Matsushita T, Tei K, Yamaguchi M, Kurosaka M (2011) The use of an electromagnetic measurement system for anterior tibial displacement during the Lachman test. Arthroscopy 27(6):792-802

14. Knoop J, Dekker J, Klein JP, Van Der Leeden M, Van Der Esch M, Reiding D, Voorneman RE, Gerritsen M, Roorda LD, Steultjens MP, Lems WF (2012) Biomechanical factors and physical examination findings in osteoarthritis of the knee: associations with tissue abnormalities assessed by conventional radiography and high-resolution 3.0 tesla magnetic resonance imaging. Arthritis Res Ther 14(5): 1

15. Miyazaki T, Uchida K, Wada M, Sato M, Sugita D, Shimada S, Baba H (2012) Anteroposterior and varus-valgus laxity of the knee increase after stair climbing in patients with mild osteoarthritis. Rheumatol Int 32(9):2823-2828

16. Vauhnik R, Morrissey MC, Rutherford OM, Turk Z, Pilih IA, Pohar M (2008) Knee anterior laxity: a risk factor for traumatic knee injury among sports women? Knee Surg Sports Traumatol Arthrosc 16(9):823-833

17. Myer GD, Ford KR, Paterno MV, Nick TG, Hewett TE (2008) The effects of generalized joint laxity on risk of anterior cruciate ligament injury in young female athletes. Am J Sports Med 36(6):1073-1080

18. Ramesh R, Von Arx O, Azzopardi T, Schranz P (2005) The risk of anterior cruciate ligament rupture with generalised joint laxity. J Bone Joint Surg Br 87(6):800-803

19. Wells GA, Shea B, O'Connell D et al (2004) The NewcastleOttawa Scale (NOS) for assessing the quality of nonrandomised studies in metaanalyses. http://www.ohri.ca/programs/clinical_ epidemiology/oxford.htm. Accessed 6 Oct 2016

20. Chen J, Gu A, Jiang H, Zhang W, Yu X (2015) A comparison of acute and chronic anterior cruciate ligament reconstruction using lars artificial ligaments: a randomized prospective study with a 5-year follow-up. Arch Orthop Trauma Surg 135(1):95-102

21. Zaffagnini S, Grassi A, Muccioli GM, Tsapralis K, Ricci M, Bragonzoni L, Della Villa S, Marcacci M (2014) Return to sport after anterior cruciate ligament reconstruction in professional soccer players. Knee 21(3):731-735

22. Guo L, Yang L, Duan XJ, He R, Chen GX, Wang FY, Zhang $Y$ (2012) Anterior cruciate ligament reconstruction with bonepatellar tendon-bone graft: comparison of autograft, fresh-frozen allograft, and $\gamma$-irradiated allograft. Arthroscopy 28(2):211-217

23. Laoruengthana A, Pattayakorn S, Chotanaputhi T, Kosiyatrakul A (2009) Clinical comparison between six-strand hamstring tendon and patellar tendon autograft in arthroscopic anterior cruciate ligament reconstruction: a prospective, randomized clinical trial. J Med Assoc Thail 92(4):491

24. Zhao J, He Y, Wang J (2007) Double-bundle anterior cruciate ligament reconstruction: four versus eight strands of hamstring tendon graft. Arthroscopy 23(7):766-770

25. Ghalayini S, Helm A, Bonshahi A, Lavender A, Johnson D, Smith R (2010) Arthroscopic anterior cruciate ligament surgery: results of autogenous patellar tendon graft versus the Leeds-Keio synthetic graft: five year follow-up of a prospective randomised controlled trial. Knee 17(5):334-339
26. Mutsuzaki H, Kanamori A, Ikeda K, Hioki S, Kinugasa T, Sakane M (2012) Effect of calcium phosphate-hybridized tendon graft in anterior cruciate ligament reconstruction a randomized controlled trial. Am J Sports Med 40(8):1772-1780

27. Porter MD, Shadbolt B (2016) Femoral aperture fixation improves anterior cruciate ligament graft function when added to cortical suspensory fixation an in vivo computer navigation study. Orthop J Sports Med 4(9):2325967116665795

28. Ghodadra NS, Mall NA, Grumet R, Sherman SL, Kirk S, Provencher MT, Bach BR (2012) Interval arthrometric comparison of anterior cruciate ligament reconstruction using bone-patellar tendon-bone autograft versus allograft do grafts attenuate within the first year postoperatively? Am J Sports Med 40(6): 1347-1354

29. Price R, Stoney J, Brown G (2010) Prospective randomized comparison of endobutton versus cross-pin femoral fixation in hamstring anterior cruciate ligament reconstruction with 2-year follow-up. ANZ J Surg 80(3):162-165

30. Pugh L, Mascarenhas R, Arneja S, Chin PY, Leith JM (2009) Current concepts in instrumented knee-laxity testing. Am J Sports Med 37(1):199-210

31. Rose T, Hepp P, Venus J, Stockmar C, Josten C, Lill H (2006) Prospective randomized clinical comparison of femoral transfixation versus bioscrew fixation in hamstring tendon ACL reconstruction: a preliminary report. Knee Surg Sports Traumatol Arthrosc 14(8):730-738

32. Sandon A, Werner S, Forssblad M (2015) Factors associated with returning to football after anterior cruciate ligament reconstruction. Knee Surg Sports Traumatol Arthrosc 23(9):2514-2521

33. Lin H, Hsu H, Chang C, Lai W (2009) Analyzing anterior knee laxity with an arthrometer for assisting diagnosis of anterior cruciate ligament rupture. In: IEEE 35th annual northeast bioengineering conference. IEEE, pp 1-2

34. Sernert N, Helmers J, Kartus C, Ejerhed L, Kartus J (2007) Kneelaxity measurements examined by a left-hand-and a right-handdominant physiotherapist, in patients with anterior cruciate ligament injuries and healthy controls. Knee Surg Sports Traumatol Arthrosc 15(10):1181-1186

35. Ahldén M, Sernert N, Karlsson J, Kartus J (2012) Outcome of anterior cruciate ligament reconstruction with emphasis on sexrelated differences. Scand J Med Sci Sports 22(5):618-626

36. Lindström M, Strandberg S, Wredmark T, Felländer-Tsai L, Henriksson M (2013) Functional and muscle morphometric effects of ACL reconstruction: A prospective CT study with 1 year followup. Scand J Med Sci Sports 23(4):431-442

37. Teitsma XM, van der Hoeven H, Tamminga R, de Bie RA (2014) Impact of patient sex on clinical outcomes data from an anterior cruciate ligament reconstruction registry, 2008-2013. Orthop J Sports Med 2(9):2325967114550638

38. Ahldén M, Sernert N, Karlsson J, Kartus J (2013) A prospective randomized study comparing double-and single-bundle techniques for anterior cruciate ligament reconstruction. Am J Sports Med 2013:2484-2491

39. Gobbi A, Mahajan V, Karnatzikos G, Nakamura N (2012) Singleversus double-bundle ACL reconstruction: is there any difference in stability and function at 3-year followup? Clin Orthop Relat Res 470(3):824-834

40. Gong X, Jiang D, Wang YJ, Wang J, Ao YF, Yu JK (2013) Second-look arthroscopic evaluation of chondral lesions after isolated anterior cruciate ligament reconstruction single-versus doublebundle reconstruction. Am J Sports Med 41(10):2362-2367

41. Hofbauer M, Valentin P, Kdolsky R, Ostermann R, Graf A, Figl M, Aldrian S (2010) Rotational and translational laxity after computer-navigated single-and double-bundle anterior cruciate ligament reconstruction. Knee Surg Sports Traumatol Arthrosc 18(9):1201-1207 
42. Järvelä T, Moisala AS, Paakkala T, Paakkala A (2008) Tunnel enlargement after double-bundle anterior cruciate ligament reconstruction: a prospective, randomized study. Arthroscopy 24(12):1349-1357

43. Kanaya A, Ochi M, Deie M, Adachi N, Nishimori M, Nakamae A (2009) Intraoperative evaluation of anteroposterior and rotational stabilities in anterior cruciate ligament reconstruction: lower femoral tunnel placed single-bundle versus double-bundle reconstruction. Knee Surg Sports Traumatol Arthrosc 17(8):907-913

44. Lao ML, Chen JH, Wang CJ, Siu KK (2013) Functional outcomes of y-graft double-bundle and single-bundle anterior cruciate ligament reconstruction of the knee. Arthroscopy 29(9):1525-1532

45. Lee S, Kim H, Jang J, Seong SC, Lee MC (2012) Comparison of anterior and rotatory laxity using navigation between single-and double-bundle ACL reconstruction: prospective randomized trial. Knee Surg Sports Traumatol Arthrosc 20(4):752-761

46. Monaco E, Labianca L, Conteduca F, De Carli A, Ferretti A (2007) Double bundle or single bundle plus extraarticular tenodesis in ACL reconstruction? a CAOS study. Knee Surg Sports Traumatol Arthrosc 15(10): 1168-1174

47. Ohkawa S, Adachi N, Deie M, Nakamae A, Nakasa T, Ochi M (2012) The relationship of anterior and rotatory laxity between surgical navigation and clinical outcome after ACL reconstruction. Knee Surg Sports Traumatol Arthrosc 20(4):778-784

48. Park SJ, Jung YB, Jung HJ, Jung HJ, Shin HK, Kim E, Song KS, Kim GS, Cheon HY, Kim S (2010) Outcome of arthroscopic single-bundle versus double-bundle reconstruction of the anterior cruciate ligament: a preliminary 2-year prospective study. Arthroscopy 26(5):630-636

49. Streich NA, Friedrich K, Gotterbarm T, Schmitt H (2008) Reconstruction of the ACL with a semitendinosus tendon graft: a prospective randomized single blinded comparison of double-bundle versus single-bundle technique in male athletes. Knee Surg Sports Traumatol Arthrosc 16(3):232-238

50. Ventura A, Legnani C, Terzaghi C, Borgo E (2012) Singleand double-bundle anterior cruciate ligament reconstruction in patients aged over 50 years. Arthroscopy 28(11):1702-1709

51. Jiang D, Ao YF, Gong X, Wang YJ, Luo H, Chen LX, Wang HJ, Xie X, Zhang JY, Yu JK (2012) Double-bundle anterior cruciate ligament reconstruction using bone-patellar tendon-bone allograft technique and 2- to 5-year follow-up. Am J Sports Med 40(5):1084-1092

52. Zhang Q, Zhang S, Li R, Liu Y, Cao X (2007) Comparison of two methods of femoral tunnel preparation in single-bundle anterior cruciate ligament reconstruction: a prospective randomized study. Acta Cir Bras 27(8):572-576

53. Edgar CM, Zimmer S, Kakar S, Jones H, Schepsis AA (2008) Prospective comparison of auto and allograft hamstring tendon constructs for ACL reconstruction. Clin Orthop Relat Res 466(9):2238-2246

54. Sun K, Zhang J, Wang Y, Xia C, Zhang C, Yu T, Tian S (2011) Arthroscopic anterior cruciate ligament reconstruction with at least 2.5 years' follow-up comparing hamstring tendon autograft and irradiated allograft. Arthroscopy 27(9):1195-1202

55. Tian S, Wang B, Liu L, Wang Y, Ha C, Li Q, Yang X, Sun K (2016) Irradiated hamstring tendon allograft versus autograft for anatomic double-bundle anterior cruciate ligament reconstruction midterm clinical outcomes. Am J Sports Med 44(10):2579-2588

56. Noh JH, Yi SR, Song SJ, Kim SW, Kim W (2011) Comparison between hamstring autograft and free tendon achilles allograft: minimum 2-year follow-up after anterior cruciate ligament reconstruction using endobutton and intrafix. Knee Surg Sports Traumatol Arthrosc 19(5):816-822

57. Laxdal G, Sernert N, Ejerhed L, Karlsson J, Kartus JT (2007) A prospective comparison of bone-patellar tendon-bone and hamstring tendon grafts for anterior cruciate ligament reconstruction in male patients. Knee Surg Sports Traumatol Arthrosc 15(2):115-125

58. Zouita Ben Moussa A, Zouita S, Dziri C, Ben Salah FZ (2009) Single-leg assessment of postural stability and knee functional outcome two years after anterior cruciate ligament reconstruction. Ann Phys Rehabil Med 52(6):475-484

59. Svensson M, Sernert N, Ejerhed L, Karlsson J, Kartus JT (2006) A prospective comparison of bone-patellar tendon-bone and hamstring grafts for anterior cruciate ligament reconstruction in female patients. Knee Surg Sports Traumatol Arthrosc 14(3):278-286

60. Dejour D, Vanconcelos W, Bonin N, Saggin PRF (2013) Comparative study between mono-bundle bone-patellar tendonbone, double-bundle hamstring and mono-bundle bone-patellar tendon-bone combined with a modified lemaire extra-articular procedure in anterior cruciate ligament reconstruction. Int Orthop 37(2):193-199

61. Park SY, Oh H, Park SW, Lee JH, Lee SH, Yoon KH (2012) Clinical outcomes of remnant-preserving augmentation versus doublebundle reconstruction in the anterior cruciate ligament reconstruction. Arthroscopy 28(12):1833-1841

62. Zhang Z, Gu B, Zhu W, Zhu L, Li Q, Du Y (2013) Arthroscopic single-bundle versus triple-bundle anterior cruciate ligament reconstruction. Acta Orthop Traumatol Turc 48(4):413-418

63. Lee JK, Lee S, Lee MC (2016) Outcomes of anatomic anterior cruciate ligament reconstruction: bone-quadriceps tendon graft versus double-bundle hamstring tendon graft. Am J Sports Med 44(9):2323-2329

64. de Pádua VBC, Maldonado H, Vilela JCR, Provenza AR, Monteiro C, de Oliveira Neto HC (2012) Comparative study of ACL reconstruction with anatomical positioning of the tunnels using the patellar tendon versus hamstring tendon. Rev Bras Ortop 47(1):50-56

65. Chouteau J, Benareau I, Testa R, Fessy MH, Lerat JL, Moyen B (2008) Comparative study of knee anterior cruciate ligament reconstruction with or without fluoroscopic assistance: a prospective study of 73 cases. Arch Orthop Trauma Surg 128(9):945-950

66. Fleming BC, Fadale PD, Hulstyn MJ, Shalvoy RM, Oksendahl HL, Badger GJ, Tung GA (2012) The effect of initial graft tension after anterior cruciate ligament reconstruction a randomized clinical trial with 36-month follow-up. Am J Sports Med 41(1):25-34

67. Koga H, Muneta T, Yagishita K, Ju YJ, Sekiya I (2012) The effect of graft fixation angles on anteroposterior and rotational knee laxity in double-bundle anterior cruciate ligament reconstruction evaluation using computerized navigation. Am J Sports Med 40(3):615-623

68. Plaweski S, Cazal J, Rosell P, Merloz P (2006) Anterior cruciate ligament reconstruction using navigation a comparative study on 60 patients. Am J Sports Med 34(4):542-552

69. Stener S, Ejerhed L, Sernert N, Laxdal G, Rostgård-Christensen L, Kartus J (2010) A long-term, prospective, randomized study comparing biodegradable and metal interference screws in anterior cruciate ligament reconstruction surgery radiographic results and clinical outcome. Am J Sports Med 38(8):1598-1605

70. Stengel D, Casper D, Bauwens K, Ekkernkamp A, Wich M (2009) Bioresorbable pins and interference screws for fixation of hamstring tendon grafts in anterior cruciate ligament reconstruction surgery a randomized controlled trial. Am J Sports Med 37(9):1692-1698

71. Moisala AS, Järvelä T, Paakkala A, Paakkala T, Kannus P, Järvinen M (2008) Comparison of the bioabsorbable and metal screw fixation after ACL reconstruction with a hamstring autograft in MRI and clinical outcome: a prospective randomized study. Knee Surg Sports Traumatol Arthrosc 16(12):1080-1086 
72. Laxdal G, Kartus J, Eriksson BI, Faxén E, Sernert N, Karlsson J (2006) Biodegradable and metallic interference screws in anterior cruciate ligament reconstruction surgery using hamstring tendon grafts prospective randomized study of radiographic results and clinical outcome. Am J Sports Med 34(10):1574-1580

73. Harilainen A, Sandelin J (2009) A prospective comparison of 3 hamstring ACL fixation devices-rigidfix, bioscrew, and intrafixrandomized into 4 groups with 2 years of follow-up. Am J Sports Med 37(4):699-706

74. Ho WP, Lee CH, Huang CH, Chen CH, Chuang TY (2014) Clinical results of hamstring autografts in anterior cruciate ligament reconstruction: a comparison of femoral knot/press-fit fixation and interference screw fixation. Arthroscopy 30(7):823-832

75. Isberg J, Faxén E, Brandsson S, Eriksson BI, Kärrholm J, Karlsson J (2006) Early active extension after anterior cruciate ligament reconstruction does not result in increased laxity of the knee. Knee Surg Sports Traumatol Arthrosc 14(11):1108-1115

76. Goradia VK, Grana WA, Pearson SE (2006) Factors associated with decreased muscle strength after anterior cruciate ligament reconstruction with hamstring tendon grafts. Arthroscopy 22(1):80-e1

77. Ito Y, Deie M, Adachi N, Kobayashi K, Kanaya A, Miyamoto A, Nakasa T, Ochi M (2007) A prospective study of 3-day versus 2-week immobilization period after anterior cruciate ligament reconstruction. Knee 14(1):34-38
78. Myer GD, Ford KR, Foss KDB, Rauh MJ, Paterno MV, Hewett TE (2014) A predictive model to estimate knee-abduction moment: implications for development of a clinically applicable patellofemoral pain screening tool in female athletes. J Athl Train 49(3):389-398

79. Klyne DM, Keays SL, Bullock-Saxton JE, Newcombe PA (2012) The effect of anterior cruciate ligament rupture on the timing and amplitude of gastrocnemius muscle activation: a study of alterations in emg measures and their relationship to knee joint stability. J Electromyogr Kinesiol 22(3):446-455

80. Barcellona MG, Morrissey MC, Milligan P, Amis AA (2014) The effect of thigh muscle activity on anterior knee laxity in the uninjured and anterior cruciate ligament-injured knee. Knee Surg Sports Traumatol Arthrosc 22(11):2821-2829

81. Kvist J (2005) Sagittal tibial translation during exercises in the anterior cruciate ligament-deficient knee. Scand J Med Sci Sports 15(3): 148-158

82. Boeth H, Duda GN, Heller MO, Ehrig RM, Doyscher R, Jung T, Moewis P, Scheffler S, Taylor WR (2013) Anterior cruciate ligament-deficient patients with passive knee joint laxity have a decreased range of anterior-posterior motion during active movements. Am J Sports Med 41(5):1051-1057 